\title{
REFLEXÕES E DISCURSOS SOBRE A VIDA HUMANA: NOVOS SUBSÍDIOS PARA AULAS DE CIÊNCIAS
}

\section{Thoughts and discourse about human life: new elements for science lessons}

Fernanda Veneu-Lumb ${ }^{1}$ Marco Antonio Ferreira da Costa ${ }^{2}$

Resumo: Objetivou-se, aqui, analisar os discursos científico e religioso, de professores de ciências do Ensino Médio, e de representantes do senso comum (perfis variados, maiores de 18 anos, que não estão envolvidos diretamente na discussão sobre o tema, e não pertencem aos demais grupos estudados), sobre a definição de vida humana. Nesta pesquisa, com abordagem qualitativa, utilizaram-se entrevistas semiestruturadas para a coleta de dados. Os dados foram analisados sob vários olhares teóricos. As "falas" dos sujeitos foram registradas e analisadas por meio de interpretação simples, buscando-se identificar os significados mais importantes. Ao se conjugarem múltiplos discursos, pretendeu-se gerar subsídios a serem utilizados em ambientes de educação formal e não formal em biociências e saúde. Ao se sistematizarem discursos que ordinariamente não são vistos juntos, e este é o ineditismo da pesquisa, buscou-se fornecer informações abrangentes para uso em aulas de ciências sobre vida humana, e, dessa forma, contribuir, significativamente, para o processo ensino-aprendizagem de ciências.

Palavras-chave: Ensino de ciências. Ensino Médio. Discurso científico.

\begin{abstract}
This study aimed to analyze and compare the discourse presented by scientists, religious representatives, science high school teachers and the so called "men on the street" (defined here as people above 18 years old, holding different professional and personal profiles and not related to the issue investigated) on the definition of human life. This was qualitative research, using semi structured interviews for collecting the data to be analyzed. Data analysis was made based on different theoretical perspectives. The discourses were registered and analyzed, through simple interpretation. The intention is to provide assistance to be used in formal educational and casual environments in bioscience and health. By classifying discourses that are not ordinarily seen together, and this is the main objective of this exclusive research, we intend to give full information and understanding, that can be used in science lessons. This is our contribution for the for teaching-and learning process in science.
\end{abstract}

Key words: Science teaching. Scientific discourse. High school.

\footnotetext{
${ }^{1}$ Membro da Associação Holandesa de Jornalistas Científicos (Vereniging Wetenschapsjournalisten Nederlan). Hoofdweg 1166, 2153LP, Nieuw-Vennep, Nederland. fveneu@gmail.com

${ }^{2}$ Laboratório de Educação Profissional em Técnicas Laboratoriais em Saúde, Escola Politécnica de Saúde Joaquim Venâncio, Fundação Oswaldo Cruz. Rio de Janeiro, RJ, Brasil.
} 


\section{Introdução}

Ciência e tecnologia estão na pauta de discussão de vários países, não somente no que se refere à aquisição de tecnologia, mas, também, em relação a um acesso mais equânime ao desenvolvimento científico e tecnológico como condição para a democracia, por meio da divulgação científica ou da educação (PINHEIRO; MATOS; BAZZO, 2007; CACHAPUZ; GIL-PEREZ; CARVALHO, 2005).

Esta discussão não passou ao largo das Nações Unidas, que, via Unesco, realizaram, na Índia, uma conferência mundial sobre Ensino de Ciências, Tecnologia e Matemática, em 2001 (UNESCO, 2001).

Promover uma educação científica capaz de oferecer uma visão crítica da ciência, com suas reais capacidades e possibilidades, foi um dos assuntos mais importantes debatidos nesse fórum, que reuniu 360 especialistas em educação de várias partes do mundo.

Segundo os conferencistas,

Como consequência das expectativas desmesuradas e pouco realistas de que a ciência e a tecnologia poderiam resolver os problemas do mundo, bem como do temor e do receio que parecem despertar, se faz cada vez mais importante estabelecer um ensino que ofereça uma imagem realista das capacidades e possibilidades das ciências, tecnologia e matemática. (UNESCO, 2001, p. V)

Além de estar na pauta das Nações Unidas, o ensino de ciências figura na agenda de muitos países, como França, Portugal e Inglaterra. São exemplos os trabalhos de Fourez (2003), Reis (2006) e o relatório da Câmara dos Lordes sobre ciência e tecnologia de 2000, respectivamente.

Fourez (2003) discorre sobre a necessidade de um ensino de ciências realizado de maneira interdisciplinar. Reis (2006) descreve uma experiência de formação de professores de ciências nos arredores de Lisboa e seus resultados. Já no relatório da Câmara dos Lordes (HOUSE OF LORDS, 2000), consta a necessidade de se tornar a ciência e a tecnologia mais compreensíveis para o público.

No Brasil, autores como Delizoicov, Angotti e Pernambuco (2002) destacam a distância entre o que se vê na sociedade e o que se vê na escola, quando o assunto é ciência. Afirmam, também, que a ciência extrapolou o ambiente escolar, estando presente nos meios de comunicação, sendo utilizada como parâmetro para decisões éticas, políticas e econômicas, comentando o papel da escola nestes novos tempos:

A escola está inserida neste mundo em mudança. É na tensão entre as possibilidades e os riscos criados pelo conhecimento das Ciências Naturais e sua tecnologia, que vivemos no contemporâneo. No entanto, essa tensão raramente chega a nossas salas de aula. (DELIZOICOV, ANGOTTI; PERNAMBUCO, 2002, p. 127, grifo nosso) 
Surge, então, uma pergunta: como abordar, em aulas de ciências, temas controversos (polêmicos), relacionados à ciência, como clonagem, pesquisas com células-tronco, considerando as diferentes formações, inclusive religiosas, de professores e alunos?

A discussão de temas polêmicos de ciência e tecnologia em salas de aula vem sendo tratada por alguns pesquisadores da área. Por exemplo, Ramos e Silva (2007), em seu artigo sobre a discussão de temas controversos em sala de aula, defendem um novo modelo para o ensino de ciências, em que fiquem mais evidentes as incertezas e os pontos fracos do saber científico:

Em um momento em que C\&T tornaram-se ícones de consulta para a [...] maioria das decisões tomadas em nível governamental, constituindo-se como esferas de poder dominantes nos mais variados processos em que a participação pública não tem sido regra, torna-se indispensável um outro modo de se pensar o ensino de ciências e tecnologias... um modo que revele um pouco mais desse "fazer ciência e tecnologia" e que, talvez, contribua para amenizar um processo histórico bastante enraizado de "mitificação da ciência. (RAMOS; SILVA, 2007, p. 8)

Nessa linha, Coelho e Falcão (2006) indicam a importância das aulas de ciência como espaço cultural, proporcionando, aos alunos, não apenas informação científica, mas, também, valores humanos. Afirmam:

O biólogo não se preocupa com pensamentos e sentimentos pessoais, mas o educador, sim. Concebemos o educando como alguém que se adapta ao meio ambiente com recursos de apreensão de informações e desenvolvimento de sentimentos e hábitos, capaz de reformulações e de reinvenções como forma de adaptação nos diferentes grupos sociais. (COELHO; FALCÃO, 2006, p. 1)

Outra pergunta, então, aparece: os docentes estariam preparados para esse tipo de atividade? Afinal, como afirmam os especialistas participantes da conferência da Unesco, "a maneira de ensinar é tão importante quanto o que se ensina" (UNESCO, 2001, p. V).

Nessa linha, trabalhando com futuros professores de ciências, Sepúlveda e El-Hani (2006) levantam a possibilidade dos indivíduos de conciliarem conhecimentos aparentemente contraditórios sobre determinado tema. Os autores buscaram analisar como os conhecimentos sobre religião e ciência estavam presentes nas visões de mundo de alunos de uma licenciatura em Ciências Biológicas que eram protestantes.

Sepúlveda e El-Hani (2006) queriam observar até que ponto os discursos científico e religioso poderiam conviver, nos indivíduos entrevistados. Ao aplicarem a teoria da linguagem de Bakhtin aos discursos coletados, descobriram "esforços diferenciados de negociação de significados entre a voz da ciência e a voz do conhecimento religioso" (SEPÚLVEDA; ELHANI, 2006, p. 48). A maioria dos participantes da pesquisa conciliou os discursos religioso e científico, ao passo que uma das futuras professoras rejeitou o discurso científico por com- 
pleto, adotando apenas o religioso. $\mathrm{Na}$ amostra analisada, descortinou-se um universo que ia da total aceitação até a total rejeição do discurso científico.

Ouvindo o lado de quem aprende, Coelho e Falcão (2006) realizaram uma pesquisa com percepções dos alunos de Ensino Médio em duas escolas (uma pública, outra particular), no estado do Rio de Janeiro. Os autores buscaram as representações sociais da morte entre esses estudantes. Nos depoimentos, os pesquisadores observaram a predominância de elementos religiosos sobre os científicos. E fazem um alerta:

Esta forte influência do aspecto cultural religioso nas representações sociais de morte e finitude dos seres humanos influencia suas visões de mundo (aspectos físicos, mentais e sociais) e, conseqüentemente, pode influenciar no aprendizado das ciências. Tendo já interagido com vários conceitos científicos ao longo de suas formações fundamentais e média, as idéias religiosas nos depoimentos são predominantes. (COELHO; FALCÃO, 2006, p. 12)

Poder-se-ia esperar que o contato com o pensamento científico ao longo do tempo escolar fosse provocar a predominância de elementos do discurso científico na fala desses alunos, quando o assunto era a morte. No entanto, isso não ocorreu, as visões religiosas predominaram sobre as científicas, fazendo os entrevistados discorrerem sobre o processo de exclusão e de ocultamento do tema na sociedade, ao longo dos últimos séculos, e sobre o pouco desenvolvimento do assunto nas salas de aula.

Estes aportes anteriores mostram a importância de um acesso equânime à ciência e à tecnologia, mas de forma crítica e com uma linguagem adequada, sobretudo temas de natureza controversa, que suscitam, necessariamente, "nos diferentes atores sociais envolvidos, posicionamentos políticos, sensibilidades éticas e estéticas diversificadas ou diferentes maneiras de interpretar uma dada realidade" (SILVA; CARVALHO, 2007, p. 7).

\section{Vida e vida humana em sala de aula}

Entre os temas não abordados com frequência em sala de aula, escolhemos "vida humana". Atualmente, muitas questões sobre a vida humana têm sido levantadas em todo o mundo. Exemplos são: a eutanásia, a pena de morte, o uso de células-tronco embrionárias humanas em pesquisas, entre outros.

Para isto, começamos a buscar bibliografia. Não encontramos muito material disponível, o que foi um dado interessante e que nos estimulou a procurar mais. Encontramos, então, material referente a "vida", apenas.

A discussão, dentro da Biologia, sobre o que é vida ainda é apresentada de forma inadequada. Emmeche (1997), assim como El-Hani e Kawasaki (2000), detectaram a superficialidade da discussão sobre o tema - ou, mesmo, a ausência do conceito de vida - nos livrostexto ou dicionários da área.

Nessa linha, Lima-Tavares e El-Hani (2001, p. 1) afirmam que, "na história da Biologia, a raridade das tentativas de refletir crítica e sistematicamente sobre a natureza dos seres vivos e a definição de vida causa perplexidade". 
Reflexões e discursos sobre a vida humana: ...

Entre os trabalhos realizados nesta área, destacam-se contribuições de autores como Coutinho (2005), que, com seus estudos, vem contribuindo para a construção de um perfil para o conceito biológico de vida.

No campo do ensino da Biologia, particularmente no que diz respeito ao Ensino Médio, Muller (2004) indica a existência de algumas "lacunas" no tratamento do tema vida nos Parâmetros Curriculares Nacionais (PCN). A autora afirma que o tema é tratado de maneira inadequada e incompleta, dando o exemplo a seguir:

[No volume 4 dos PCN (Ciências Naturais)], podemos verificar a afirmação de que "é possível uma primeira aproximação ao conceito de ser vivo por meio do estudo do ciclo vital: nascimento, crescimento, reprodução e morte". Da maneira como está disposto, tem-se a impressão de que a vida tem início na infância não necessitando, portanto, ser concebida e gerada. Talvez fosse o caso de perguntar: quando começa, afinal, a vida? (MULLER, 2004, p. 15)

A busca por definir vida não é recente. $\mathrm{Na}$ Grécia antiga, quando ainda não existia a divisão entre Filosofia e Ciência, filósofos como Aristóteles já se questionavam a respeito da definição e da origem da vida, do mundo e dos seres humanos. Em muitas outras mitologias e religiões milenares, há também explicações para estes fenômenos.

Porém, esta busca transcendeu a Filosofia e as mitologias em vários momentos. Destacamos, aqui, o que se viu na sociedade brasileira em 2007, quando este foi o tema da primeira audiência pública na história do Supremo Tribunal Federal (STF). Em 20 de abril de 2007, 17 cientistas compareceram ao STF, a convite do ministro Carlos Ayres Britto, integrante daquele tribunal, para responder a seguinte pergunta: onde começa a vida?

A audiência e a votação ganharam destaque nos noticiários e foram transmitidas ao vivo pela TV, em uma demonstração de que, como afirmam Bazzo, Linsingen e Pereira (2003, p. 19), "as questões relativas à ciência e à tecnologia e sua importância na definição das condições da vida humana extravasam o âmbito acadêmico para converter-se em centro de atenção e interesse do conjunto da sociedade".

Objetiva-se, aqui, contribuir para esta discussão, tendo como foco a vida humana. Não se buscará o aspecto biologicista da questão, mas as visões de grupos sociais sobre a vida humana. Portanto, este estudo tem como objetivo recolher, organizar e sistematizar os discursos sobre o que é a vida humana, produzidos por representantes de diferentes grupos sociais, como: cientistas, religiosos, professores de ciências do Ensino Médio do Rio de Janeiro, bem como os de representantes do senso comum, e buscará responder às seguintes questões:

1 Quais as visões de vida humana presentes nos grupos pesquisados?

2 Que diferenças e semelhanças existem entre essas visões?

O diferencial deste trabalho é reunir, em um só lugar, discursos que circulam na sociedade sobre a vida: suas definições, segundo cada grupo pesquisado, bem como sobre em que ponto a vida começa e onde termina. Pretende-se oferecer uma reflexão mais aprofundada sobre cada um dos discursos, bem como uma comparação não usual entre eles, aí o inedi- 
tismo do estudo, que não está disponível nos livros didáticos de Biologia ou em materiais paradidáticos, segundo trabalhos acadêmicos realizados (LIMA-TAVARES; EL HANI, 2001; EMMECHE, 1997; EL-HANI; KAWASAKI, 2000; MULLER, 2004, entre outros).

\section{Metodologia}

Para atingir os objetivos desejados, optou-se pela pesquisa teórico-descritiva, com abordagem qualitativa. Relembra-se, aqui, a finalidade real da pesquisa qualitativa, como afirma Gaskell (2004, p. 65): "explorar o espectro de opiniões, as diferentes representações do assunto em questão." Com esta escolha, realçamos as diferentes visões que se pensava encontrar sobre a vida humana.

Entre as ferramentas que este tipo de pesquisa oferece, escolheu-se a entrevista, por permitir maior possibilidade de expressão livre dos sujeitos (MINAYO, 1996). Buscou-se obter uma amostra substancial dos discursos dos próprios sujeitos, para, então, proceder à análise dos dados, feita sob a ótica de diversos olhares teóricos.

Para se obterem as informações desejadas, preparou-se um roteiro de entrevista semiestruturada. Na elaboração deste roteiro, consideraram-se as perguntas: Quais as concepções de vida humana presentes na sociedade, em particular nos grupos a estudar?; De acordo com as concepções destes grupos, em que momento a vida humana se inicia e em que momento termina?; Que diferenças e semelhanças existem entre elas?; A pluralidade sobre as concepções do que seja vida humana deve ser discutida nas escolas de Ensino Médio?. Incluíram-se, também, perguntas sobre as influências da ciência e da tecnologia, bem como do direito e da religião, na sociedade.

Nos contatos realizados com os entrevistados, deixou-se a eles a possibilidade de escolher entre o roteiro enviado por e-mail (FOINA, 2000; SHEEHAN; HOY, 1999) ou uma entrevista realizada com a pesquisadora, com o mesmo roteiro. No caso de entrevistados vivendo em outros estados, a opção pelo envio do roteiro, por e-mail, foi da pesquisadora. Todas as entrevistas foram gravadas com o consentimento dos participantes.

\section{Limitações da metodologia}

O foco foi exclusivamente nas percepções dos sujeitos pesquisados a respeito do que é vida humana, sem qualquer ligação com o enfoque biológico da questão. Não se buscou, aqui, definir vida, ou vida humana, mas, sim, recolher as percepções dos grupos escolhidos na pesquisa, com base nos seus discursos.

\section{Características dos grupos estudados}

Participaram da pesquisa 33 indivíduos: 11 professores de ciências, 12 representantes do senso comum, cinco cientistas e cinco representantes de religiões (catolicismo, espiritismo, islamismo, protestantismo/presbiterianismo, judaísmo). Todos foram informados sobre os objetivos do trabalho, tendo autorizado a realização das entrevistas, por meio da assinatura de Termos de Consentimento Livre e Esclarecido (TCLE), bem como a utilização dos dados para 
fins científicos/educacionais, mantendo-se a proteção e o anonimato dos sujeitos, de acordo com a Resolução 196/96, do Conselho Nacional de Saúde. O estudo foi aprovado pelo Comitê de Ética em Pesquisa com Seres Humanos, da Escola Politécnica de Saúde Joaquim Venâncio, Fiocruz (Parecer 2008/0042). Os grupos pesquisados possuem as seguintes características:

\section{Professores de ciências}

Foram escolhidos 11 indivíduos que atuam ou atuaram no Ensino Médio, ministrando aulas de Biologia (nove), Química (um) ou Física (um). Estes indivíduos pertencem ao meio acadêmico dos autores, ou foram indicados por representantes desse meio. Priorizaramse as entrevistas pessoais (sete) em detrimento dos roteiros enviados por e-mail (quatro).

\section{Senso comum}

Consideraram-se, para esta pesquisa, representantes do senso comum segundo a perspectiva de Alves (2002), que diz:

Prefiro não definir [o que é senso comum]. Talvez simplesmente dizer que senso comum é aquilo que não é ciência e isto inclui todas as receitas para o dia-a-dia, bem como os ideais e esperanças que constituem a capa do livro de receitas. (ALVES, 2002, p. 13, grifo do autor)

São, portanto, indivíduos de perfis variados, maiores de 18 anos, com as seguintes características em comum: não estão envolvidos diretamente na discussão sobre o tema; não são especialistas em nenhuma das áreas a serem ouvidas; não pertencem aos demais grupos estudados.

As profissões dos indivíduos pertencentes ao grupo denominado senso comum são: manicure, editor de livros, fisioterapeuta, doméstica, jornaleiro, estudante de fisioterapia, estudante de pós-graduação (doutorado em tradução), secretária, dentista, jornalista, costureira, aposentado (faz-tudo).

Também, neste caso, priorizaram-se as entrevistas pessoais (11), com apenas uma realizada por e-mail, considerando que a pessoa entrevistada vive em São Paulo.

\section{Cientistas}

Inicialmente, escolheram-se os 17 cientistas convidados pelo Supremo Tribunal Federal (STF) a participarem da audiência pública que teve como tema: "Onde começa a vida", realizada em 20 de abril de 2007. Os nomes deles foram obtidos no texto da decisão do ministro Carlos Ayres Britto, presidente do STF (BITTENCOURT, 2007).

Consultou-se, então, o currículo Lattes, em busca dos e-mails de cada um e enviou-se um e-mail inicial, contendo a proposta da pesquisa e um convite para a participação. Um dos cientistas convidados não tinha currículo Lattes disponível para consulta. Buscou-se o contato com ele de outras maneiras, mas não foi possível encontrar seu e-mail. Dos 16 cientistas contactados, cinco responderam. Destes cinco, dois alegaram outros afazeres, não podendo, por isto, participar. Enviaram-se, então, os roteiros para os outros três. Dois retornaram.

Decidiu-se, então, buscar outros cientistas. Uma das professoras de ciências do Ensino Médio entrevistadas sugeriu um nome, que foi contactado e aceitou participar da pesquisa; 
uma cientista que ministra palestras sobre células-tronco também foi convidada a participar e aceitou. Houve um contato, ainda, com um cientista de formação médica e literária, que também aceitou participar da pesquisa. Ficou-se, assim, com um total de cinco entrevistados.

Deste total, apenas uma cientista se dispôs a conceder uma entrevista. Os demais optaram por responder ao roteiro enviado por email, seja por alegarem falta de tempo, seja por não estarem no Rio de Janeiro.

\section{Religiões}

As religiões foram escolhidas, em parte, por observação dos resultados do Censo 2000 do Instituto Brasileiro de Geografia e Estatística (IBGE), como foi o caso do catolicismo (mais de 124 milhões de indivíduos), do evangelismo (mais de 26 milhões de fiéis), do espiritismo (mais de duas milhões e duzentas mil pessoas) e da umbanda (mais de 397 mil adeptos), em parte por serem religiões que mantêm uma tradição milenar, como o judaísmo, o islamismo e o budismo (INSTITUTO BRASILEIRO DE GEOGRAFIA E ESTATÍSTICA, 2001). Em todas elas, buscaram-se os representantes "institucionais", que pudessem responder pela religião tendo alguma inserção na hierarquia. O objetivo foi reduzir a possibilidade de se encontrarem discursos divergentes em uma mesma religião, ao se buscar a posição oficial de cada uma. Consultaram-se, então, as seguintes instâncias:

- catolicismo: Confederação Nacional dos Bispos do Brasil (CNBB), em Brasília, e Vicariato Episcopal Norte, no Rio de Janeiro. O retorno foi dado pelo Vicariato Norte ${ }^{3 ;}$

- espiritismo: Federação Espírita do Brasil (FEB), em Brasília;

- judaísmo: Federação Israelita do Estado do Rio de Janeiro e contato pessoal com um rabino. O retorno foi dado pelo rabino;

- umbanda: Conselho Nacional da Umbanda do Brasil (Conub), seção Rio de Janeiro;

- islamismo: Sociedade Beneficente Muçulmana do Rio de Janeiro;

. budismo: Federação das Seitas Budistas do Brasil e Comunidade Zen Budista Zendo Brasil, em São Paulo; biteriana.

- protestantismo: contato pessoal com um pastor protestante, de denominação pres-

Destas, responderam ao contato: catolicismo, espiritismo, judaísmo, islamismo e protestantismo (presbiterianismo). À exceção do espiritismo, cuja representante vive em Brasília, todos foram entrevistados em seus locais de trabalho (igrejas católica e protestante, Associação Beneficente Muçulmana, um clube judaico que tem sinagoga).

\section{Características de gênero}

Segundo o gênero (Tabela 1), foram ouvidos 17 homens e 16 mulheres. Vale lembrar que quatro dos cinco representantes das religiões entrevistados eram do sexo masculino (exceção foi o espiritismo). Quanto aos demais grupos, houve predominância do sexo feminino nos representantes do senso comum (oito mulheres para quatro homens), leve predominância do sexo masculino nos representantes dos cientistas (três homens, duas mulheres).

\footnotetext{
${ }^{3}$ Vicariato Norte é a parte territorial da Arquidiocese de São Sebastião. É formado por quarenta paróquias, sendo uma do rito maronita, localizadas em 24 bairros da cidade do Rio de Janeiro.
} 
Reflexões e discursos sobre a vida humana: ...

O sexo masculino também acabou por predominar levemente nas entrevistas dos professores de biologia (seis homens, cinco mulheres).

Tabela 1. Amostra segundo o sexo, por grupos

\begin{tabular}{lccc}
\hline Grupos & Homens & Mulheres & Total (por grupo) \\
\hline Professores & 06 & 05 & 11 \\
Senso comum & 04 & 08 & 12 \\
Religiosos & 04 & 01 & 05 \\
Cientistas & 03 & 02 & 05 \\
\hline
\end{tabular}

Fonte: Veneu-Lumb, 2009.

\section{Análise dos dados}

As etapas da análise constaram dos seguintes passos, adaptados de Minayo, Souza e Constantino (2008): transcrição de entrevistas, atribuição de códigos aos entrevistados, leitura comparativa dos textos das entrevistas, articulação entre os sentidos encontrados nos depoimentos, busca por categorias que reunissem o maior número de falas possível.

As entrevistas, realizadas pessoalmente, foram transcritas, ouvidas e lidas muitas vezes. Os dados oriundos dos roteiros enviados por e-mail também foram criteriosamente analisados. Esse processo analítico procurou semelhanças e diferenças nos discursos gerados.

No tratamento dos dados, os indivíduos foram nomeados com a letra inicial do grupo a que pertenciam e numerados segundo a ordem das entrevistas. Por exemplo: primeira entrevista com um(a) cientista: código C1; primeira entrevista com um professor: P1; primeira entrevista do senso comum: SC1, e os entrevistados do grupo dos religiosos, citados pela religião específica (solicitaram-se, aos representantes das religiões, a posição oficial de cada religião).

\section{Resultados e discussão}

\section{Perfil por religiões}

Dos 33 entrevistados, cinco eram representantes das religiões (católica, espírita, muçulmana, protestante e judaica). Entre os professores entrevistados, seis afirmaram não ter religião, quatro são católicos, e um, espírita. Dos cinco cientistas, três não têm religião. Os outros dois pertencem às religiões judaica e evangélica, respectivamente. Quatro dos representantes do senso comum professam a fé católica; três, outras religiões; três afirmam não ter religião; um é espírita, e uma, evangélica.

Em praticamente todas as entrevistas, houve pausas como resposta imediata a algumas das perguntas. Registraram-se, também, logo após a pausa, comentários como: "pergunta difícil!", ou interjeições como "nossa!". Depois, os entrevistados passavam a responder as questões. Após a entrevista, alguns relataram que nunca tinham pensado no assunto daquela ma- 
neira antes, o que nos faz esperar que, apenas com as perguntas, já tenhamos começado a contribuir para uma reflexão sobre o tema.

Cabe retomar aqui a afirmação de Cobern $(1993,2000)$ de que perguntas de caráter mais amplo poderiam inviabilizar a variedade de respostas. Neste trabalho, a pluralidade e variedade de definições para vida humana foi notável. Não houve respostas iguais, nem entre os grupos, nem entre indivíduos do mesmo grupo. Observaram-se, sim, elementos comuns nas respostas, mas não houve uma idêntica à outra. Optou-se, aqui, em primeiro lugar, por agrupá-las, para se obter uma visão mais geral, para, depois, trabalhar suas diversidades, semelhanças e diferenças.

Destes entrevistados, dez definiram vida humana utilizando elementos do discurso científico. Destes dez, dois pertencem ao senso comum; quatro, ao grupo de professores; dois eram representantes de religiões (catolicismo e espiritismo). Os outros dois eram cientistas.

Elementos do discurso religioso estão presentes em 11 depoimentos (cinco do senso comum, dois professores, quatro religiosos). Encontrou-se apenas uma menção a elementos do discurso religioso entre os cientistas.

Entre os professores e os representantes do senso comum, elementos relacionados à maneira de viver (respeito pelos demais, viver o momento em lugar de tentar definir vida etc.) estiveram presentes em seis respostas (quatro professores e dois do senso comum).

O senso comum comportou a maior variedade de definições. Além das já mencionadas, houve: apreciações, como "não tá sendo muito bom, mas também não está sendo ruim"; generalizações, como "tudo!"; "é o bem maior".

Um professor de Biologia e dois cientistas, em lugar de definirem a vida humana, optaram por dizer onde ela começa. Estes foram contabilizados separadamente. Observam-se, na Tabela 2, as respostas classificadas por grupo.

Tabela 2. Características dos discursos por grupo, em relação ao que é vida humana

\begin{tabular}{lcccccc}
\hline $\begin{array}{c}\text { Características } \\
\text { do discurso / } \\
\text { grupos }\end{array}$ & $\begin{array}{c}\text { Elementos } \\
\text { do discurso } \\
\text { científico }\end{array}$ & $\begin{array}{c}\text { Elementos } \\
\text { do discurso } \\
\text { religioso }\end{array}$ & $\begin{array}{c}\text { Elementos } \\
\text { relacionados à } \\
\text { maneira de viver }\end{array}$ & $\begin{array}{c}\text { Onde a vida } \\
\text { começa? }\end{array}$ & $\begin{array}{c}\text { Outros } \\
\text { Total por } \\
\text { grupo }\end{array}$ \\
\hline Professores & 04 & 02 & 04 & 01 & 0 & 11 \\
Senso comum & 02 & 05 & 02 & 0 & 04 & 12 \\
Religiosos & 02 & 04 & & 02 & 0 & 05 \\
Cientistas & 02 & 01 & & 05 \\
\hline
\end{tabular}

OBS: Alguns discursos contêm elementos de mais de uma característica e, por isso, foram contabilizados em mais de uma classificação.

Fonte: Veneu-Lumb, 2009.

Os cientistas que têm religião (2) tiveram posições antagônicas. Um deles (C2), de religião evangélica, identifica sua resposta pessoal com a que dá em relação a sua religião: "Já respondi. Os objetivos desta criação estão em parte descritos na Bíblia".

Já C5, de religião judaica, assinala sua discordância em relação ao que pensam alguns segmentos do judaísmo: "Alguns rabinos acham isso e aquilo. E eu acho diferente, porque apesar de ser 
Reflexões e discursos sobre a vida humana: ...

judia, eu não acho nem uma coisa, nem outra. Eu acho que a vida começa quando se estabelece uma relação mãe-filho". Nota-se aqui, mais uma vez, que, na resposta, aparece a informação sobre onde a vida começa, e não uma conceituação/percepção sobre a vida humana.

\section{Análise das falas}

Para analisar as falas dos entrevistados, utilizaram-se as categorias propostas por Coutinho, Mortimer e El Hani (2007), com algumas adaptações. Os pesquisadores, na busca por construírem um perfil para o conceito biológico de vida, trabalharam, inicialmente, com sete categorias para classificar as falas dos entrevistados. Estas categorias foram reduzidas, posteriormente, a três:

. externalismo - "uma compreensão da vida como algo externo e separado do vivente, que pode ser entendida como algo que vem de fora ou que tende a uma finalidade para além do ser vivo" (COUTINHO, MORTIMER; EL HANI, 2007, p. 24);

. internalismo - "os entrevistados estão explicitando uma compreensão da vida como processos, propriedades ou entidades inerentes ao vivente" (COUTINHO, MORTIMER; EL HANI, 2007, p. 24);

. relacional - "a vida é entendida como uma relação entre entidades e/ ou sistemas, ou seja, a definição de vida é dada em termos de relações" (COUTINHO, MORTIMER; EL HANI, 2007, p. 24).

Dos 33 entrevistados, 24 definiram vida segundo a categoria externalismo, como nos exemplos a seguir (grifos nossos): "A vida humana foi criada por Deus, é vontade de Deus, é bênção de Deus e tem o cuidado de Deus." (protestantismo); "Na verdade, a vida em si é quando você [...] tem a alma." (islamismo); "Para mim, a vida é a do espírito (parte imaterial do ser). O corpo físico é apenas um 'bardware' onde a mente/alma (espirito se manifesta). A vida, a consciência, a vontade própria, a criatividade não são oriundos do corpo, mas sim do espirito" (C2).

Observa-se, nos trechos selecionados, a ideia de vida como algo exterior ao ser vivo. No caso do protestantismo, criação de Deus. Os depoimentos do islamismo e de C2 contêm elementos metafísicos, como "alma" e "espírito".

$\mathrm{Na}$ categoria internalismo, encontraram-se falas como a deste professor: "Eu encaro a vida como a continuidade do ser humano de perpetuar a espécie. Na realidade, você tem as células, que, juntas - a célula do homem, o espermatozóide, e o óvulo - que vão criando a vida no caso do ser humano. [...] na realidade, você tem a junção das duas células que se transformam em uma nova vida. Um ser que vai nascer, crescer e morrer" (P5), grifos nossos.

Como comentado por Coutinho, Mortimer e El-Hani (2007, p. 124), os entrevistados estão explicitando "uma compreensão da vida como processos, propriedades ou entidades inerentes ao vivente".

$\mathrm{Na}$ categoria relacional, encontraram-se exemplos como os que estão a seguir: "[...] $e$ o momento de a gente aprender alguma coisa". (P9); "[a vida humana] é uma coisa maravilhosa 
quando a gente sabe viver. É difícil a gente saber viver, isso é que é difícil." (SC 12); "É algo muito valioso que devemos cuidar com todo o carinho, não importando se ela é sua ou se é do outro, pois, uma vez. perdida, não tem retorno". (P11)

Menções a saber viver, a cuidar da própria vida e da do semelhante são características destas e de outras falas relacionadas a esta categoria, encontradas na pesquisa. Observou-se, também, em alguns casos, a ocorrência de mais de uma categoria.

Um dos exemplos mais evidentes foi a fala do rabino, em que se misturaram as categorias externalismo e relacional: "Na verdade, pra mim, vida é uma criação de Deus. Ponto. O que deu vida para os animais, o que deu vida para o ser humano? [...] Os animais foram criados para servir ao ser humano". (externalismo/metafísica). "Quer diz̨er, que a vida é pra servir, então o ser humano [...] também foi criado para servir. Agora, servir quem? Nós acreditamos que tem de servir o criador que criou ele. Então, definindo: a vida é... serviço" (relacional) (grifos nossos).

No discurso de P3, existe uma mistura das categorias externalismo e internalismo. "Vou te responder que é um milagre, é uma mágica. Não um milagre de Deus, mas um milagre da própria natureza. A vida bumana não tinha muito como dar certo. Mas ta dando". (externalismo)/[...] A vida, em si [...] é uma organização particular de matéria” (internalismo) (grifos nossos).

\section{Considerações finais}

A definição de vida humana não é consenso, nem mesmo entre os indivíduos de cada grupo entrevistado. Verificaram-se, ao longo da pesquisa, pontos comuns nos depoimentos dos diversos grupos sociais, mas não uniformidade de significados para a vida humana.

Palavras e conceitos pertencentes à ciência estão presentes em todos os grupos pesquisados, $\mathrm{o}$ que nos faz atentar para a influência que a ciência exerce na sociedade.

Além da ciência, a religião desempenhou um papel importante nos discursos dos entrevistados, à exceção dos cientistas, que utilizaram apenas o saber técnico/científico para descrever o que era a vida humana, para eles, como indivíduos.

Nas falas dos religiosos, observou-se menção à ciência ou de termos científicos no catolicismo e no espiritismo. Os demais representantes das religiões definiram vida por características mais subjetivas, como dom de Deus (protestantismo), serviço (judaísmo), quando [...] tem a alma (islamismo).

Já nas respostas dos professores de ciências, observaram-se misturas de palavras, expressões e conceitos ligados à ciência com outros relacionados à religião e ao comportamento. Surgem conceitos como aprendizado, no sentido religioso, e de viver o momento, assim como menções ao lado científico do tema.

No senso comum, a variedade de conceitos também marcou. Aparecem, nos discursos, misturas de elementos religiosos e de ciências, bem como menções ao comportamento: viver bem, aproveitar o dom que foi dado a cada um, entre outras.

Muller (2004) constatou, em seu estudo, brechas nos Parâmetros Curriculares Nacionais (PCN), na maneira de abordar a vida e a morte, no estudo de ciências do Ensino Médio. Toda esta pluralidade de significados em relação à vida humana e assuntos correlatos também poderia ser utilizada no ensino de Ciências, considerando-se essas diferentes visões nas intera- 
ções de sala de aula. Essa estratégia poderia gerar ganhos significativos para a compreensão de um tema, ao mesmo tempo, antigo e atual.

Deste modo, podem-se transformar as brechas nos PCN, apontadas por Muller (2004), em instrumentos de qualificação do aluno, oferecendo a ele possibilidades cada vez mais amplas de pensar sobre si e sobre o mundo ao seu redor, conhecendo as diferentes faces daquilo que está sendo estudado, sobretudo quando se tratam de temas controversos, que devem, por natureza, ser tratados com uma abordagem social.

Não podemos nos esquecer de que tratar desses assuntos em sala de aula depende muito, também, da competência docente dos profissionais envolvidos nos processos ensinoaprendizagem de Ciências. Esses devem ter claramente a noção de que estar em sala de aula tratando de conteúdos que envolvem ciência, religião, ideologias, por exemplo, necessita, obrigatoriamente, de uma mediação aberta e abrangente, com o uso intensivo de estratégias didáticas, como: aulas interativas; trabalhos em grupos; debates, entre outras.

Portanto, esperamos, com este estudo, contribuir para uma discussão mais ampla sobre o tema, levando, para a sala de aula, outras vozes e diferentes discursos, além do científico.

\section{Referências}

ALVES, R. O senso comum e a ciência. In: . Filosofia da ciência: introdução ao jogo e a suas regras. 4. ed. São Paulo: Loyola, 2002. Disponível em: $<$ http:// ceticismo.wordpress.com/2006/11/20/o-senso-comum-e-a-ciencia/>. Acesso em: 23 mar. 2008.

BAZZO, W. A.; LINSINGEN, I. V.; PEREIRA, L. T. V. (Ed.). Introdução aos estudos CTS (ciência, tecnologia e sociedade). Madrid: Organização dos Estados Ibero-americanos para a Educação, a Ciência e a Cultura, 2003.

BITTENCOURT, F. Células-tronco vão ao Superior Tribunal Federal (STF). Correio Unifesp, São Paulo, 2007. Disponível em: <http://www.neurofisiologia.unifesp.br/ celulatroncostf.htm\#decisao >. Acesso em: 10 jun. 2008.

BRASIL. Presidência da República. Lei n. 11.105, de 24 de março de 2005. Disponível em: < http://www.planalto.gov.br/ccivil_03/_ato2004-2006/2005/lei/111105.htm>. Acesso em: 10 out. 2008.

Conselho Nacional de Saúde. Diretrizes e normas regulamentadoras de pesquisas envolvendo seres humanos. Resolução 196, 1996. Disponível em <http:// www.bioetica.ufrgs.br/res19696.htm> Acesso em: 2 mar.2009.

CACHAPUZ, A.; GIL-PEREZ, D.; CARVALHO, A. M. P. (Org.) A necessária renovação do ensino das ciências. São Paulo: Cortez, 2005. 
Veneu-Lumb, F.; Costa, M. A. F.

COBERN, W. W. College students' conceptualizations of nature: an interpretative world view analysis. Journal of Research in Science Teaching, New York, v. 30, n. 8, p. 935-951, 1993.

Everyday thoughts about nature. Dordrecht: Kluwer, 2000.

COELHO, F. J. F.; FALCÃO, E. B. M. Ensino científico e representações sociais de morte humana. Revista Iberoamericana de Educación, Madrid, v. 39, n. 3, p. 1-14, 2006.

Disponível em: <http://www.rieoei.org/deloslectores/1230Figueiredo.pdf>. Acesso em: 08 ago. 2008.

COUTINHO, F. A. Construção de um perfil conceitual de vida. 2005. 183 f. Tese (Doutorado em Educação) - Faculdade de Educação, Universidade Federal de Minas Gerais, Belo Horizonte, 2005.

COUTINHO, F. A.; MORTIMER, E. F.; EL-HANI, C. N. Construção de um perfil para o conceito biológico de vida. Investigações em Ensino de Ciências, Porto Alegre, v. 12, n. 1, p. 115-137, 2007.

DELIZOICOV, D.; ANGOTI, J. A.; PERNAMBUCO, M. M. Ensino de ciências: fundamentos e métodos. São Paulo: Cortez, 2002.

EL-HANI, C. N.; BIZZO, N. M. V. Formas de construtivismo: mudança conceitual e construtivismo contextual. Ensaio: pesquisa em educação em ciências, Belo Horizonte, v. 4, n. 1, p. 37-58, 2002.

EL-HANI, C. N.; KAWASAKI, C. S. Contribuições da biologia teórica para o ensino de biologia. I. É possível definir vida? In: ENCONTRO PERSPECTIVAS DO ENSINO DE BIOLOGIA, 7. E SIMPÓSIO LATINO-AMERICANO DA IOSTE, 1., São Paulo, 2000.

Coletânea... São Paulo: Universidade de São Paulo: Faculdade de Educação, 2000. p. 27-31.

EMMECHE, C. Defining life, explaining emergence. In: PRINCETON HISTORY OF SCIENCE WORKSHOP ON GROWING EXPLANATIONS, Princeton, 1997. Disponível em: < http://www.nbi.dk/ emmeche/cePubl/97e.defLife.v3f.html>. Acesso em: 10 mar. 2010.

FOINA, A. G. Métodos de aquisição de dados quantitativos na internet: o uso da rede como fonte de dados empíricos. Educação Brasileira, Brasília, v. 22, n. 44, p. 155-166, jan/jul. 2000.

FOUREZ, G. Crise no ensino de ciências? Investigações em Ensino de Ciências, 2003 v.8 (2). Disponível em <http://www.if.ufrgs.br/ienci/artigos/Artigo_ID99/ v8_n2_a2003.pdf>

GASKELL, G. Entrevistas individuais e grupais. In: BAUER, M. W.; GASKELL, G. Pesquisa qualitativa com texto, imagem e som: um manual prático. Petrópolis: Vozes, 2004. p. 64-89. 
Reflexões e discursos sobre a vida humana: ...

House of Lords. Third Report on Science and Technology, march 2000. Disponível em < http://www.publications.parliament.uk/pa/ld199900/ldselect/ldsctech/38/3801.htm> Acesso em: 25 mar. 2009.

INSTITUTO BRASILEIRO DE GEOGRAFIA E ESTATÍSTICA. Censo 2000. Rio de Janeiro: IBGE, 2001.

KAWASAKI, C. S.; EL HANI, C. N. Uma análise das definições de vida encontradas em livros didáticos de biologia do ensino médio. In: ENCONTRO PERSPECTIVAS DO ENSINO DE BIOLOGIA, 8., São Paulo, 2002. Anais... São Paulo, 2002. p. 1-6.

LIMA-TAVARES, M.; EL-HANI, C. N. Um olhar epistemológico sobre a transposição didática da teoria Gaia. Investigações em Ensino de Ciências, Porto Alegre, v. 6, n. 3, p. 299-336, 2001. Disponível em: <http://www.if.ufrgs.br/public/ensino/vol6/n3/ v6n3a4.htm>. Acesso em: 10 mar. 2008.

MINAYO, M. C. S. (Org.). Pesquisa social: teoria, método e criatividade. 13. ed. Petrópolis: Vozes, 1996.

MINAYO, M. C. S; SOUZA, E. R.; CONSTANTINO, P. Missão prevenir e proteger: condições de vida, trabalho e saúde dos policiais militares do Rio de Janeiro. Rio de Janeiro: Editora Fiocruz, 2008.

MULLER, G. C. K. Alcances e fragilidades: os temas de vida e morte nos livros didáticos. 2004. 199 f. Dissertação (Mestrado em Educação) - Universidade Regional de Blumenau, Blumenau, 2004.

NUNES, C. M. F. Saberes docentes e formação de professores: um breve panorama da pesquisa brasileira. Educação e Sociedade, São Paulo, v. 22, n. 74, p. 27-42, 2003.

ORGANIZACION DE LOS ESTADOS AMERICANOS. Convención Interamericana de Derechos Humanos. São Jose da Costa Rica, 1969. Disponível em: <http:// www.oas.org/Juridico/spanish/tratados/b-32.html>. Acesso em: 23 jul. 2008.

PINHEIRO, N. A. M.; MATOS, E. A. S. A; BAZZO, W. A. Refletindo acerca da ciência, tecnologia e sociedade: enfocando o ensino médio. Revista Iberoamericana de Educación, Madrid, n. 44, mayo/ago., 2007. Disponível em: <http://www.rieoei.org/ rie44a08.htm>. Acesso em: 08 ago. 2011.

RAMOS, M. B.; SILVA, H. C. Para pensar as controvérsias científicas em aulas de ciências. Ciência \& Ensino, Campinas, v. 1, p. 1-16, 2007. (Número especial). Disponível em: <http://www.ige.unicamp.br/ojs/index.php/cienciaeensino/article/viewFile/132/106>. Acesso em: 11 mar. 2010.

REIS, P. Uma iniciativa de desenvolvimento profissional para a discussão de controvérsias sociocientíficas em sala de aula. Portugal, Interacções, 2006 n.4. p. 64-107. Disponível em $<$ http://nonio.eses.pt/interaccoes/artigos/D4.pdf $>$ Acesso realizado em 20 de novembro de 2008 . 
Veneu-Lumb, F.; Costa, M. A. F.

SEPÚLVEDA, C.; EL HANI, C. Apropriação do discurso científico por alunos protestantes de biologia: uma análise à luz da teoria da linguagem de Bakhtin. Investigações em Ensino de Ciências, Porto Alegre, v. 7, n. 1, p. 29-51, 2006.

SHEEHAN, K. B.; HOY, M. G. Using e-mail to survey internet users in the United State: methodology and assessment. Journal of Computer-Mediated Communication, Hoboken, v. 14, n. 3, 1999. Disponível em: <http://jcmc.indiana.edu/vol4/issue3/ sheehan.html>. Acesso em: 11 mar. 2010.

SILVA, L. F.; CARVALHO, L. M. A temática ambiental e o processo educativo: o ensino de física a partir de temas controversos. Ciência \& Ensino, Campinas, v. 1, 2007. (Número especial). Disponível em: <http://www.ige.unicamp.br/ojs/index.php/cienciaeensino/ article/viewFile/152/105>. Acesso em: 05 abr. 2009.

UNESCO. Organização das Nações Unidas para a Educação, a Ciência e a Cultura, La enseñanza de las ciências, la tecnologia y las matemáticas en pro del desarrollo humano. Marco de Acción. Disponível em <http://unesdoc.unesco.org/images/0012/001274/ 127417S.pdf>. Acesso em: 9 jun. 2009.

VENEU-LUMB, F. A. E a vida humana, o que é? O diálogo entre a ciência, a religião, os professores e o senso comum: enriquecendo o ensino de Ciências.102p. Tese. (Doutorado em Ciências). Rio de Janeiro: Instituto Oswaldo Cruz, Fundação Oswaldo Cruz, 2009.

Artigo recebido em 01/08/2011. Aceito em 28/11/2011. 